\title{
Comparison between Heat Flow Meter (HFM) and Thermometric (THM) Method for Building Wall Thermal Characterization: Latest Advances and Critical Review
}

\author{
Luca Evangelisti *, Andrea Scorza (D), Roberto De Lieto Vollaro (D) and Salvatore Andrea Sciuto (D)
}

Citation: Evangelisti, L.; Scorza, A.; De Lieto Vollaro, R.; Sciuto, S.A. Comparison between Heat Flow Meter (HFM) and Thermometric (THM) Method for Building Wall Thermal Characterization: Latest Advances and Critical Review. Sustainability 2022, 14, 693. https:// doi.org/10.3390/su14020693

Academic Editor: Antonio Caggiano

Received: 16 December 2021 Accepted: 7 January 2022 Published: 9 January 2022 Corrected: 18 October 2022

Publisher's Note: MDPI stays neutral with regard to jurisdictional claims in published maps and institutional affiliations.

Copyright: (c) 2022 by the authors. Licensee MDPI, Basel, Switzerland. This article is an open access article distributed under the terms and conditions of the Creative Commons Attribution (CC BY) license (https:/ / creativecommons.org/licenses/by/ $4.0 /)$.
Department of Industrial, Electronic and Mechanical Engineering, Roma Tre University, 00146 Rome, Italy; andrea.scorza@uniroma3.it (A.S.); roberto.delietovollaro@uniroma3.it (R.D.L.V.); salvatore.sciuto@uniroma3.it (S.A.S.)

* Correspondence: luca.evangelisti@uniroma3.it

\begin{abstract}
It is well-known that on-site measurements are suitable for verifying the actual thermal performance of buildings. Performance assessed in situ, under actual thermal conditions, can substantially vary from the theoretical values. Therefore, experimental measurements are essential for better comprehending the thermal behavior of building components, by applying measurement systems and methods suitable to acquire data related to temperatures, heat flows and air speeds both related to the internal and external environments. These data can then be processed to compute performance indicators, such as the well-known thermal transmittance (U-value). This review aims at focusing on two experimental techniques: the widely used and standardized heat flow meter (HFM) method and the quite new thermometric (THM) method. Several scientific papers were analyzed to provide an overview on the latest advances related to these techniques, thus providing a focused critical review. This paper aims to be a valuable resource for academics and practitioners as it covers basic theory, in situ measurement equipment and criteria for sensor installation, errors, and new data post-processing methods.
\end{abstract}

Keywords: review article; thermal transmittance (U-value); in situ measurements; heat flow meter (HFM) method; thermometric (THM) method

\section{Introduction}

Nowadays, the concept of energy efficient and sustainable building is widely accepted and pursued [1]. New constructions are built following specific energy saving techniques and technology, both from a passive and active point of view. Although the main objective of the environmental performance of buildings is associated with the use of carbon, it is nevertheless necessary to consider the thermal performance of building fabrics as a key factor [2]. The energy issues also require integration with the concept of well-being and sustainability. It is therefore easy to understand how the concept of a comfortable, healthy, and low energy impact building is not just a matter of state-of-the-art and well-integrated systems.

The result of what has been said so far leads to the broader concept of holistic vision [3]. The holistic view in the building sector results in the application of the principles of bioecological architecture. Technicians are in front of a comparison between the reality and considerations of historical traditions, environment, culture, using the new principles of sustainability, biocompatibility, energy saving and the use of renewable sources [4].

Within this context, the performance of the building envelope has a significant role. The thermal performance is quantified in terms of heat loss, and it is usually expressed in the building sector as thermal resistance (R-value) or thermal transmittance (U-value) [5]. U-value is the heat transfer rate across a building component, divided by the difference in temperature across the structure. On the contrary, the R-value is the inverse of the thermal 
transmittance, being the capability of a building component to resist heat fluxes. The thermal transmittance calculation is mandatory when establishing construction strategies. Walls U-value is the most significant factor influencing building energy performance [6,7]. It is worthwhile to observe that one of the most effective ways to reduce a building's energy requirements is to improve the U-values of its walls [8].

New buildings can be realized following detailed design criteria in terms of wall stratigraphy, transparent components, and air-conditioning systems. In this case, the U-value of walls can be computed through the theoretical method cited in the Standard ISO 6946 [9], which is based on the well-known thermal-electrical analogy. It defines the thermal resistance of a layer made of a specific material as the ratio between its thickness and the thermal conductivity of the material. This theoretical approach leads to the idea of thermal resistance, and it can be applied to the building of walls. For components characterized by a known stratigraphy, each layer can be symbolized by a thermal resistance.

Conversely, the situation is rather complicated in existing constructions, where the thermal performance of their components needs to be investigated. This can be related to the lack of technical data (lost in time) or to constructive changes along time [10]. It is worth noting that it can be difficult to accurately identify the thermal properties of building materials [11]. This can be particularly challenging in historic buildings and existing heritage due to the technological complexity of the structures and the effects of ageing and weathering on materials [12,13].

Moreover, the design of thermal engineering systems cannot ignore the comprehension of the energy performance of the building envelope. This means that the basic principles of correct system design lie in the preliminary understanding of the thermal behavior of the envelope.

This concept is more evident if applied to a design from scratch. In this case, the choices of the technicians are absolutely detached from any architectural constraint. As already mentioned, it is necessary to discern new buildings and existing ones. In new buildings, each structural element is known, as selected after specific assessments that determine the performance that designers intend to provide to the structure. In existing buildings, it is necessary to perform specific evaluations, case by case, to avoid errors in the estimation of heat transfer and U-values. Estimating wrong U-values can have a double effect: precluding interventions in buildings with poor energy performance or leading to the application of unnecessary and expensive energy efficiency interventions [14-16].

Therefore, experimental U-value measurements are essential for better comprehending the thermal behavior of building components, applying sensors able to acquire data related to temperatures, heat flows and air speeds both related to the indoor and outdoor environments. These data can then be processed to compute performance indicators, such as the already mentioned U-value.

Several noteworthy in situ measurement techniques can be found in the literature. In particular, the standardized heat flow meter (HFM) method, the so-called thermometric (THM) method, the simple hot box HFM method (called SHB-HFM in brief) and the quantitative infrared thermography approach (named QIRT in brief) have been examined. Figure 1 shows the percentage distribution of research articles related to the different experimental techniques [17] found using the Web of Science database. It is possible to observe that only $4 \%$ of the research is related to the THM method, highlighting that this simple method has not been investigated much by the scientific community and it could have development chances. This highlights the existing discrepancies in terms of research interests and efforts in the field of in situ experimental techniques. 


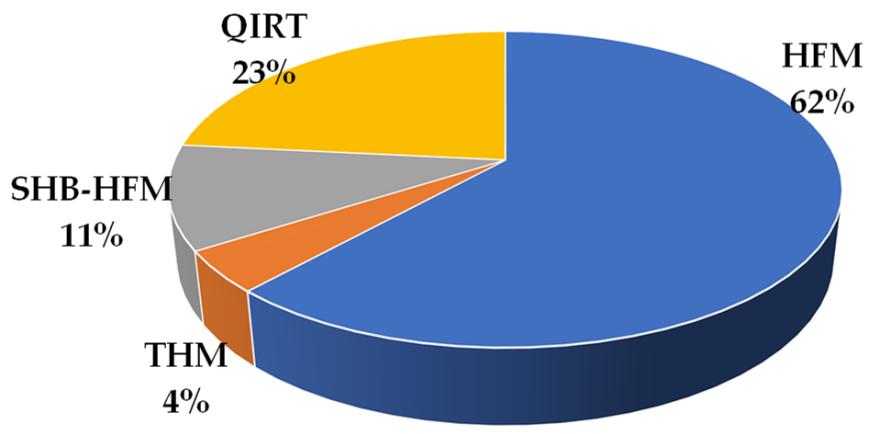

Figure 1. Percentage distribution of research articles related to the different experimental techniques found using the Web of Science database.

Some authors reviewed all these methods together [18] highlighting pros and cons. Nevertheless, an important factor that essentially makes all these techniques relevant only to those who have many (and sometimes expensive) measuring instruments and sensors was not considered. As such, what has been said so far needs to be placed side by side with the pragmatic issue of sensors availability and costs, whose estimates have not been taken into consideration in the already published reviews (Table 1 lists the approximate costs related to the different experimental techniques often reviewed in the literature). Technicians may not have all the required measurement instruments and sensors that research laboratories may have. Moreover, it has already been observed in other review papers that the QIRT approach requires very specific environmental conditions. An ideal constant heat transfer state should be reached for 3 or $4 \mathrm{~h}$ before the test. Wind, clear sky conditions and sun rays can alter the results of test. From a practical point of view, measurements should be done before sunrise [17]. On the other hand, the SHB-HFM method requires the construction of a small hot box, with additional costs. This method is limited by the supplementary structure needed when the hot box is positioned outside (it is only appropriate for walls on the ground floor). Additionally, the SHB-HFM method cannot be applied when the ground floor I is dissimilar from the other floors [18]. If we tried to use these methods for the energy requalification of existing buildings, the number of measures to be carried out would be high and their application would not be feasible. We may need (i) a very long time to perform measurements, or (ii) many sensors and measuring instruments for simultaneous acquisitions. This would be unfeasible considering the price and processing costs [19].

For these reasons, this review is based on the latest scientific papers focusing only on two experimental techniques: the widely used and standardized HFM method and the quite new THM method, not adequately revised in other review articles (not all scientific works that applied this method were considered). The first technique is based on a direct heat flow measure through heat flow sensors applied on the inner side of walls, also acquiring data related to indoor and outdoor temperatures. On the contrary, the second one is based on an indirect approach, based only on temperature measurements, where suitable total heat transfer coefficients need to be used for computing heat flows crossing walls. Furthermore, it is worth pointing out that both methods are widely used by engineers and architects, both for energy audits and for scientific research, and the test conditions are similar. Figure 2 shows a schematic comparison among the theoretical, HFM and THM methods for achieving U-values, highlighting similarities and differences among the needed sensors for the experimental approaches.

It is worthwhile to observe that the latest review papers found in the literature $[17,18]$ did not examine all the research articles related to the THM method, which would appear to be promising for speed, simplicity and lower cost compared to the HFM method. Therefore, this paper aims at providing an overall view about works and data processing related to the THM method, including a focused review where the THM method is placed side by 
side with the well-known, widely used and standardized HFM technique, also considering the theoretical method frequently used as a reference for experimental data validation.

Theoretical method (ISO 6946)

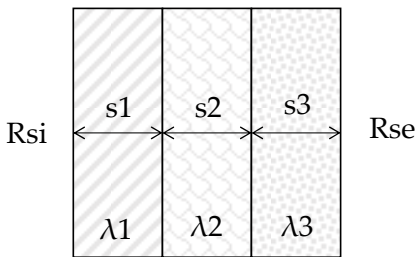

HFM method (ISO 9869-1)

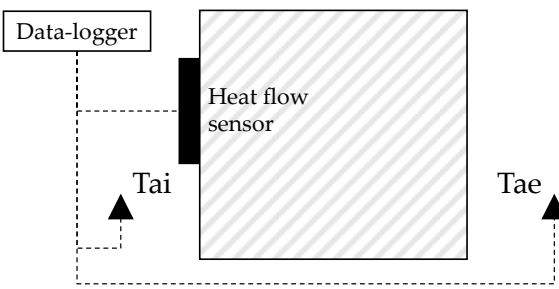

THM method

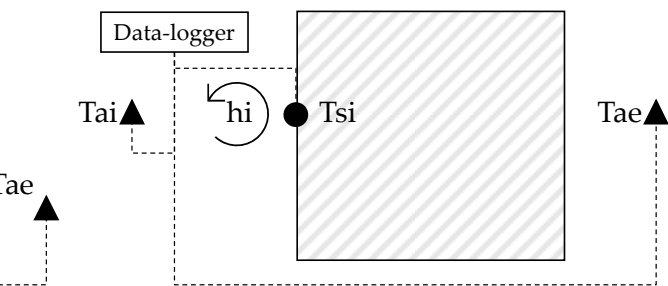

Figure 2. Theoretical, HFM and THM methods for obtaining U-values (where Rsi is the internal surface resistance; Rse is the external surface resistance; Tai is the internal air temperature; Tae is the external air temperature; $T s i$ is the inner surface temperature; $h i$ is the internal heat transfer coefficient; $s$ is the thickness of each layer and $\lambda$ is the thermal conductivity of each layer).

Starting from this, the review is structured in the following manner: Section 2 provides the background theory behind the theoretical approach, HFM and THM methods, considering that the theoretical approach is often applied for comparing experimental results and theoretical reference values; Section 3 provides a description of the equipment for measurements; Section 4 analyzes errors and uncertainties; Section 5 provides the latest advances in terms of data analysis; finally, Section 6 draws the conclusions, highlighting future research developments.

Table 1. Experimental methods applied to determine walls' U-value.

\begin{tabular}{ccc}
\hline Method & $\begin{array}{c}\text { Measuring Instruments and } \\
\text { Sensors (Number) }\end{array}$ & $\begin{array}{c}\text { Example of Sensor Costs }{ }^{1} \\
{[\boldsymbol{\epsilon}]}\end{array}$ \\
\hline \multirow{2}{*}{ Heat flow meter method } & Heat flow plate (1) & 700.00 \\
(HFM) & Temperature probe (2) & 320.00 \\
& Datalogger (1) & 900.00 \\
\hline \multirow{3}{*}{ Thermometric method (THM) } & Temperature probe (2) & 320.00 \\
& Surface temperature probe (1) & 115.00 \\
& Datalogger (1) & 900.00 \\
\hline Simple hot box HFM method & Heat flow plate (3) & 2100.00 \\
(SHB-HFM) & Temperature probe (1) & 160.00 \\
& Surface temperature probe (9) & 1035.00 \\
& Datalogger (1) & 900.00 \\
\hline Quantitative infrared & Simple hot box (1) & - \\
\hline thermography method (QIRT) & Infrared camera (1) & up to about 30,000.00 \\
& Anemometer (1) & 600.00 \\
& Surface temperature probe (1) & 320.00 \\
\hline
\end{tabular}

${ }^{1}$ Costs based on the authors' experience.

\section{Background Theory behind the Methods}

This section aims at providing the background theory behind the theoretical approach, HFM and THM methods to obtain a global view about the theoretical knowledge and the resulting needs in terms of future developments based on the literature review.

As already mentioned, the theoretical method cited in the Standard ISO 6946 [9] is based on the well-known thermal-electrical analogy. This approach brings us to the thermal resistance concept. It can be applied for building walls, characterized by known stratigraphy. Consequently, the total thermal resistance of a wall can be assessed considering both the structure and the internal and external heat transfer, in terms of surface thermal 
resistances. There is a correlation between thermal transmittance and thermal resistance because one is the inverse of the other:

$$
U=\frac{1}{R_{t o t}}=\frac{1}{R_{s, i}+\sum_{i} R_{i}+R_{s, e}}
$$

where $R_{t o t}$ is the total thermal resistance of the wall; $R_{i}$ is the $i$-th layer thermal resistance; $R_{s, i}$ and $R_{s, e}$ are the internal and external surface thermal resistances. The ISO 6946 recommends $0.13 \mathrm{~m}^{2} \mathrm{~K} / \mathrm{W}$ and $0.04 \mathrm{~m}^{2} \mathrm{~K} / \mathrm{W}$ for $R_{s, i}$ and $R_{s, e}$, respectively. The above-mentioned values for $R_{s, i}$ and $R_{s, e}$ can be carried out from inner and outer overall heat transfer coefficients, defined for specific boundary conditions and equal to $7.69 \mathrm{~W} / \mathrm{m}^{2} \mathrm{~K}$ and $25 \mathrm{~W} / \mathrm{m}^{2} \mathrm{~K}$, respectively. Taking into account the internal surface of a wall, for horizontal heat fluxes the standard refers to a convective heat transfer coefficient of $2.5 \mathrm{~W} / \mathrm{m}^{2} \mathrm{~K}$, but no additional information is provided regarding this value.

The main advantage of the theoretical method is that it provides U-values using a simple calculation without requiring experimental measurements. Nevertheless, a proper U-value calculation is challenging due to the possible lack of information in terms of technical data, both related to walls compositions and material thermophysical properties. Therefore, the theoretical method is suitable for a first approach during building design. On the other hand, the results can be affected by a high degree of uncertainty when used in existing buildings, also related to an accurate evaluation of the surface thermal resistances [20]. It should also be noted that in building materials databases, thermal conductivities range between a minimum and a maximum value based on the material's density [21]. It is very difficult to correctly identify a material and assign it a correct thermophysical property due to problems related to the identification of walls stratigraphy, heterogeneities, moisture, ageing and weathering effects [22].

From an experimental point of view, walls thermal transmittance (or total thermal resistance) can be evaluated through the HFM method, which is a standardized experimental technique (measurements need to be performed according to the standard ISO 9869-1 [23]). This experimental approach requires the recording of heat fluxes crossing wall and the indoor-outdoor air temperature differences, relying on well-known heat transmission mechanisms. The U-value (or the R-value) is the heat transfer coefficient that relates heat flux to the temperature difference, according to the following equation:

$$
q=U\left(T_{a, i}-T_{a, e}\right)=\frac{T_{a, i}-T_{a, e}}{R_{t o t}}
$$

where $q$ is the heat flux density, $U$ is the thermal transmittance of the wall, $T_{a, i}$ is the indoor air temperature, $T_{a, e}$ is the outdoor air temperature and $R_{t o t}$ the total thermal resistance of the wall, previously defined. According to Equation (2), the U-value can therefore be obtained. U-values are logged for each recording step, providing instantaneous values. It is worth noting that for the measurement of surface temperatures instead of air temperatures, the wall thermal conductance can be found.

On the other hand, the thermometric method (THM) is quite a new and straightforward, non-standardized technique [18]. It is a temperature-based approach, also known in the literature as the air-surface temperature ratio (ASTR) technique [24]. It is a nondestructive technique for determining the U-values of walls through an indirect heat flux measurement. THM can be considered an indirect heat flow measurement because it requires two temperature probes, through which the temperature of the inner surface of the wall and the indoor air temperature can be evaluated. Moreover, this approach requires the knowledge of the total internal heat transfer coefficient through which the heat flux crossing the wall is calculated. The theory behind this method is the Newton's law of cooling [25], through which the following equation can be written:

$$
Q=h A\left(T_{S}-T\right)
$$


where $Q$ is the heat flux, $h$ is the surface heat transfer coefficient, $A$ is the surface area, $T_{S}$ is the surface temperature of the body and $T$ is the surrounding temperature. The Application of Equation (3) to a building wall when $T_{a, i}>T_{a, e}$, can be rewritten in the following manner:

$$
Q=h_{t o t, i} A\left(T_{a, i}-T_{s, i}\right)
$$

where $h_{t o t, i}$ is the internal total heat transfer coefficient, $T_{a, i}$ is the indoor air temperature and $T_{s, i}$ is the inner surface temperature of the wall. Making Equations (2) and (4) equal, the U-value can be assessed as follows:

$$
U=\frac{h_{t o t, i}\left(T_{a, i}-T_{s, i}\right)}{T_{a, i}-T_{a, e}}
$$

It is worth noting that the most important issue is the accurate assessment of the internal heat transfer coefficient. It is challenging to characterize the thermal resistance between two points because it is related to material properties, and it needs the understanding of all the parameters required for defining $h_{t o t, i}$.

\section{Equipment for Measurements}

\subsection{HFM Method}

As mentioned before, by applying the HFM method, thermal transmittance measurements can be performed measuring heat fluxes and air temperatures, logging data in a data-logger or other data acquisition systems. The heat flow measurements are usually carried out by thermopile heat flow sensors: they generally consist of circle or square slim plates with a known thermal resistance, equipped with thermopiles for evaluating the temperature difference across the sides of their sensitive surface. The thermocouples of the thermopile are contained in a moisture-proof plate with appropriate mechanical properties. The estimation of the heat flux density can be done by measuring the temperature on both sides of the sensor and using a specific calibration curve. Heat flux sensors for on-site measurements are usually characterized by few millimeters' plates, made of stiff or flexible plastic material. These sensors must be correctly installed on the internal surface of the wall, preventing contact resistances. When walls have high surface roughness, thermal conductive paste needs to be applied to avoid the insulating effects caused by the air pockets. Furthermore, a preliminary thermographic survey should be performed in order to exclude cold bridges at the installation point of the heat flow sensor $[21,26]$. Thermal bridges can cause deviations from the one-dimensional heat flow conditions, altering the measurement. Moreover, to avoid incorrect measurements, the heat flow sensor (and the fixing materials) should have the same radiative characteristics of the wall surface. Peng and $\mathrm{Wu}$ [27] proposed plastering the heat flow sensor or embedding it in the surface, in order to avoid discrepancies between heat flow sensors and walls. The air temperature probes consist of two high-precision air temperature sensors, with a maximum error of $\pm 0.5^{\circ} \mathrm{C}$ or less [28]. To exclude convective and radiative heat transfer between the surfaces of the wall and the surroundings, some dynamic methods need the measurement of the internal and external wall surface temperatures rather than air temperatures. Regarding the sensors' position, it is worthy to observe that the heat flow sensor should be installed $1.5 \mathrm{~m}$ above the floor [29], far from cold bridges [30], and at least $1.3 \mathrm{~m}$ from fan coils or radiators to avoid incorrect measurements [31]. Internal and external air temperature sensors should be installed $30 \mathrm{~cm}$ or $40 \mathrm{~cm}$ from the vertical surface of the wall to avoid convective effects [18,32]. However, it is worthy to observe that, frequently, technicians must adapt the position of sensors to the specific characteristics of the environments where such measurements are performed. Temperatures and air velocity inside a building commonly fluctuate between floor and ceiling in the function of specific thermal and fluid dynamics phenomena. Therefore, the acquired data can be influenced by the mutual position of sensors [24]. 


\subsection{THM Method}

On the other hand, for obtaining U-values, the THM method requires a datalogger and temperature sensors. Two air temperature sensors are necessary to log indoor and outdoor air temperatures, and surface temperature probes are required for the inner surface temperatures of the wall. Commercial systems based on this method, commonly used by professionals in the field, usually apply the $h_{t o t, i}$ fixed design value suggested by the ISO $6946[29,33]$. Internal surface temperature sensors should be properly installed on the inner surface of the wall, avoiding any structural anomaly such as a mortar joint between bricks or cold bridges. This requires a thermal imaging camera to analyze the building envelope before testing. The air temperature probes should be positioned as well aligned as possible, $30 \mathrm{~cm}$ or $40 \mathrm{~cm}$ from the wall to prevent convective effects [18]. An improved methodological approach suggested by Evangelisti et al. [34,35], based on the experimental identification of surface thermal resistances, is based on the evaluation of convective phenomena able to influence the convective heat transfer coefficient. The knowledge of all the parameters necessary to define the convective coefficients is fundamental, and it involves the use of a hot-wire anemometer to measure air velocity near the wall surface, in order to perform an empirical analysis based on the dimensionless groups. Obviously, this approach requires one more measuring instrument, increasing the total cost of the measuring apparatus (see Table 1).

\section{Errors and Uncertainties}

\subsection{HFM Method}

Despite the common use of the HFM method, some issues have been highlighted from a metrological and operational point of view. The measurement uncertainty is primarily associated to the heat flow sensor [25]. The heat flow sensor installed on the wall can alter the heat flux, consequently affecting the resulting U-value [36,37]. The principal contributor to measurement uncertainty is the heat flow plate [27], and inaccurate installations strongly affect the behavior of the wall from a thermal perspective [38]. It has been demonstrated that inaccuracies ranging from $26 \%$ [39] to $30 \%$ [40] can be related to heat-flow sensors. Uncertainties ranging between $2 \%$ and $5 \%$ are related to poor contacts between heat flow sensors and the internal surface of the wall. Non-one-dimensional heat flows can contribute with uncertainties in the range of $1-5 \%$ [20]. Moreover, practices for protecting wall surfaces during in situ measurements (such as installing a PVC film) can cause U-value deviations ranging from $19 \%$ to $21 \%$ [41]. Different heights between the heat flow plate and the internal air temperature sensor can affect the results with inaccuracies ranging between $17 \%$ and $22 \%$ [24]. The wall orientation also has a fundamental role in obtaining reliable thermal transmittance values. Facades facing east, west, and south are characterized by different heat flow rates when compared to facades facing north. It is related to the sun path, with thermal inversions caused by solar radiation. Due to the wall's orientation, comparing experimental and theoretical values, an error of about $37 \%$ has been observed in terms of the U-value [42]. Specific external environmental conditions in terms of wind, rain, and snow, can also affect the results. It was observed that wind velocity can affect heat flux, with errors greater than $1.6 \%$ for wind velocities higher than $1 \mathrm{~m} / \mathrm{s}$ [43]. Tests should be performed when it is not raining or snowing, and the humidity is low. Comparing walls both under ordinary conditions and in the presence of moisture, it was found that moisture can deviate the U-value by up to $71 \%$ [44]. During tests, the operating cycles of the air conditioning systems must be taken into consideration. Convective air flows near walls can be developed by heating systems, affecting heat flux measurements. Heating phenomena related to the heating system or sun rays across windows can cause an increasing radiative and convective thermal energy. Therefore, the measured thermal flux increases unevenly with respect to the wall, resulting in a higher instantaneous thermal transmittance measurement. Although there is an increase in the U-value, this is unrelated to what is happening on the wall. At the same time, reduction of radiative/convective thermal energy can be related to heating systems shutdown. The temperature of the heat flow sensor surface drops faster than the 
temperature of the wall surface, with a reduction in terms of measured heat flux, causing a lower U-value. As such, it is important to carefully shield thermal energy sources [45]. Generally, heating systems can be considered the most suitable solution to perform thermal transmittance measurements, while air conditioning systems do not guarantee appropriate test conditions [46]. A strong indoor-outdoor temperature difference is generally required to give representative results $[47,48]$. It was demonstrated that an uncertainty equal to $10 \%$ can be obtained when the temperature difference is equal to $10{ }^{\circ} \mathrm{C}$ [5]. From a theoretical point of view, a constant temperature difference over time is essential to prevent the effect of the thermal gradient variation. However, temperature stability along time and high temperature gradients are difficult to obtain, especially for the Mediterranean climatic conditions [49]. However, findings in the literature showed that measurements with a high number of acquisitions, but characterized by a temperature difference greater than $5^{\circ} \mathrm{C}$ allowed representative results to be obtained $[5,35]$. The main problem for the HFM method seems to therefore be associated with the stability of temperatures over time rather than the temperature difference between indoor and outdoor environments.

Finally, it should be noted that the effects of aging and atmospheric agents in old buildings can affect thermal performance leading to discrepancies between experimental measurements and theoretical reference values. Specific environmental conditions protracted over time could alter the performance of walls unevenly in buildings. In these cases, one-spot measurements may therefore not be representative of the entire building and the comparison with the theoretical reference data could be misleading. Consequently, in these cases, the experimental U-values become the references and the theoretical ones can only be supposed [35].

More detailed information about the uncertainty contributions and corrective precautions are listed in Tables 2-4, referred to the measurand, the measurement chain and the environmental conditions, respectively.

Table 2. Typical uncertainty contributions and corrective actions related to the measurand (adapted from [21]).

\begin{tabular}{|c|c|c|}
\hline Cause & Experimental Notes & Uncertainty Range \\
\hline $\begin{array}{l}\text { Heat flux and temperature } \\
\text { non-uniformity }\end{array}$ & $\begin{array}{l}\text { (1) Preliminary infrared thermography survey for avoiding sensors } \\
\text { installation near thermal bridges } \\
\text { (2) Repeat measurements in different positions }\end{array}$ & $1-5 \%$ \\
\hline $\begin{array}{l}\text { Heat flux and temperature } \\
\text { instability }\end{array}$ & $\begin{array}{l}\text { (1) Sampling intervals long enough (at least } 72 \mathrm{~h} \text { ) } \\
\text { (2) Low thermal variations during measurements } \\
\text { (3) Control of indoor environmental conditions } \\
\text { (4) C-value measurement instead of U-value }\end{array}$ & $5-10 \%$ \\
\hline Heat flow meter resistance & $\begin{array}{c}\text { (1) Correction based on the thermal resistance value declared by the } \\
\text { manufacturer and the actual heat flux with no HFM sensor } \\
\text { (2) Measurement compensation by installing temperature sensors } \\
\text { under the plate }\end{array}$ & $2-3 \%$ \\
\hline Contact resistance & (1) Use of thermal conductive pastes or adhesive tapes & $2-5 \%$ \\
\hline
\end{tabular}

Table 3. Typical uncertainty contributions and corrective actions related to the measuring chain (adapted from [21]).

\begin{tabular}{ccc}
\hline Cause & Experimental Notes & Uncertainty Range \\
\hline Temperature sensors & $\begin{array}{c}\text { (1) High indoor-outdoor temperature } \\
\text { difference }\left(10^{\circ} \mathrm{C}\right)\end{array}$ & $0.1-0.2^{\circ} \mathrm{C}$ \\
(2) Frequent sensors calibration & $\begin{array}{c}\text { (1) High heat fluxes density } \\
\text { Heat flow meter }\end{array}$ & $1-2 \%$ \\
\hline
\end{tabular}


Table 3. Cont.

\begin{tabular}{ccc}
\hline Cause & Experimental Notes & Uncertainty Range \\
\hline Data acquisition system & (1) Datalogger calibration & $1-2 \%$
\end{tabular}

Table 4. Typical uncertainty contributions and corrective actions related to the environmental conditions (adapted from [21]).

\begin{tabular}{|c|c|c|}
\hline Cause & Experimental Notes & Uncertainty Range \\
\hline Temperature & $\begin{array}{c}\text { (1) Placing of HFM datalogger in controlled } \\
\text { environment }\end{array}$ & $1-2 \%$ \\
\hline $\begin{array}{l}\text { Solar radiation or other } \\
\text { thermal sources }\end{array}$ & $\begin{array}{l}\text { (1) Shading sensors by solar radiation or } \\
\text { further thermal energy sources }\end{array}$ & - \\
\hline Moisture content & (1) Proper selection of external surfaces & - \\
\hline
\end{tabular}

\subsection{THM Method}

Considering the THM technique, the main advantage of this method is related to the absence of heat flow sensors, so the measurement errors produced by the heat flow sensor can be excluded. Therefore, only errors correlated to the surface temperature sensors can be associated to the THM method. The sensors should not be mounted on mortar joints on the wall. The joints are typically tight, but care should be taken because of the errors that may result. Infrared thermography can, of course, confirm that the probes are placed in the correct position [40]. The validity of the results is not affected by the test period when there is a strong difference in temperature and the thermal conditions in the rooms are stable [32]. Other sources of uncertainty could be related to wall orientations, presence of cold bridges, solar radiation effects (thermal inversions can occur) and a good structural condition of the analyzed wall.

An empirical analysis based on the dimensionless groups can be a viable solution for computing the convective heat transfer coefficients, but in this case, a hot-wire anemometer also needs to be used $[25,35]$. Fluid dynamics phenomena generated by air flows induced by radiators or fan coils may occur and this approach allows each case study to be better investigated, providing specific coefficient values. However, an analysis related to the hot-wire anemometer position has not yet been done.

\section{Data Analysis}

\subsection{HFM Method}

Data analysis methods may have a considerable influence on the results found through the HFM method. The standard ISO 9869-1 suggests two procedures for analyzing data, the average progressive method and the dynamic one. If temperature is stable around the heat flow meter, a test duration equal to at least $72 \mathrm{~h}$ is recommended in the standard. Otherwise, this period can be longer, even more than 7 days. If the thermal regime before and during the measurement is stable, the progressive average method can be used. Conversely, the use of the dynamic method is recommended. The U-value can be calculated through the progressive average method by applying the following formula:

$$
U=\frac{\sum_{j=1}^{N} q_{j}}{\sum_{j=1}^{N}\left(T_{a, i j}-T_{a, e j}\right)}
$$

where $j$ is the single measurement acquisition, $N$ is the overall logged measurements, $q$ is the heat flux density, $T_{a, i}$ is the interior air temperature and $T_{a, e}$ is the outside air temperature. The progressive average method is certainly easy to use, nevertheless stationary conditions over time are quite difficult to have. For walls characterized by a specific heat capacity less than $20 \mathrm{~kJ} / \mathrm{m}^{2} \mathrm{~K}$, ISO 9869-1 suggests that only data acquired during nights can be used for 
the data analysis. The measurement can be stopped when the results do not differ by more than $\pm 5 \%$ after three consecutive nights. Otherwise, the test must be continued. For heavier walls, the standard requires three constraints that must all be fulfilled simultaneously. The first constraint is related to the test duration, more than $72 \mathrm{~h}$. The second constraint provides that the thermal transmittance value found at the end of the measurement must not differ by more than $\pm 5 \%$ from the value achieved $24 \mathrm{~h}$ earlier. Lastly, the U-value calculated using the data of the first period on INT(2.DT/3) days must not differ by more than $5 \%$ from the value achieved from the data relating to the previous timespan of the same duration, where DT is the test duration in days and INT is the integer component. Alternatively, the dynamic method is a black-box technique, not requiring data about the wall. It just involves some historical series of the indoor and outdoor temperatures, and the heat fluxes. This method was originally suggested by Aittomäki [50]. The thermal conductance of a wall can be found through this statistical approach. The dynamic method requires codes, such as CTSM [51], LORD [52], and MRQT [53]. Due to its complexity, the dynamic method for data analysis is not frequently applied, although some works have shown a smaller gap between the theoretical and measured U-values [54]. It has also been shown that the values obtained through this post-processing method are more accurate and have a lower variability when the measurement conditions are not optimal $[54,55]$. The standard ISO 9869-1 specifies that differences higher than 20\% between measured and theoretical U-values can be related to: incorrect thermal conductivity values assigned to the materials, incorrect surface thermal resistance values, measurements carried out under poor thermal conditions, phase changes (such as freezing, thawing or moisture), the environmental temperatures used for the calculation are not those measured. Observing the findings shown in Table 5, it is possible to affirm that in the case of walls of historic buildings, the use of tabulated methods and analytical calculations generates an underestimation of the thermal performance of the walls compared to the results found experimentally. For more recent constructions, the measured U-values are generally higher than those obtained from the calculations. Usually, experimental U-values are about $20 \%$ higher than calculated ones. A non-homogeneity in terms of measurement duration can also be observed. Despite the two standardized methods, in the literature, different approaches for filtering data have been investigated [56]. Several authors stated that the accuracy of a measurement can be enhanced by data rejection and by including only those obtained for a high temperature difference. The filtering process takes into account only data relating to an indoor-outdoor temperature difference greater than $10^{\circ} \mathrm{C}$, no rain, wind speed between $0 \mathrm{~m} / \mathrm{s}$ and $1 \mathrm{~m} / \mathrm{s}$ and start and stop of the heating system operation.

It was observed that wind and rain effects can persist from $2 \mathrm{~h}$ to $6 \mathrm{~h}$ after the rainfall [57]. Consequently, data from these timespans must be discarded. Generally, the methodology used for data processing clearly influence the results, causing differences up to $20 \%$ [58]. The linear trendline approach was proposed as a new method for data selection when measurements are conducted during winter, in environments heated by radiators [46]. The suggested method consists of creating a linear trendline for indoor air temperature data, keeping out values higher than the line in order to exclude heat flow data affected by convective and radiative effects caused by the heating system power being on. Starting from simulations and on-site measurements, this approach allows reductions to be achieved in terms of difference between the measured and the theoretical U-values. As already mentioned, temperature stability along time and high temperature gradients are difficult to obtain, especially for the Mediterranean climatic conditions [59]. For this reason, a specific data selection method based on detailed criteria was proposed by Evangelisti et al. [60] for measurements carried out under various weather conditions and wall orientations, on walls distinguished by low thermal inertia. This approach allows to manage thermal inversions and heat flow rising, by iteratively selecting data based on temperature differences and heat flux densities higher than precise values. The preliminary findings were achieved considering walls with low thermal inertia. Consequently, the suggested method must also be tested with traditional masonry, with higher thermal mass. 
Table 5. Research papers based on the comparison between HFM method and theoretical calculations.

\begin{tabular}{|c|c|c|c|c|}
\hline Authors & $\begin{array}{l}\text { Building Construction } \\
\text { Period }\end{array}$ & $\begin{array}{l}\text { Methodological } \\
\text { Approach }\end{array}$ & Measurement Time & $\begin{array}{c}\text { Average Percentage Difference } \\
\text { between Measured and } \\
\text { Theoretical Value }\end{array}$ \\
\hline Doran [61] & Before 1998 & -HFM vs. ISO 6946 & At least 14 days & $21 \%$ \\
\hline Baker [26] & Before 1919 & -HFM vs. ISO 6946 & At least 14 days & $24 \%$ \\
\hline Rye and Scott [62] & Before 1919 & -HFM vs. ISO 6946 & At least 14 days & $28 \%$ \\
\hline $\begin{array}{l}\text { Rhee-Duverne and } \\
\text { Paul Baker [63] }\end{array}$ & 18th-19th century & -HFM vs. ISO 6946 & 3 to 4 weeks & $24 \%$ \\
\hline Asdrubali et al. [64] & 2007-2008 & -HFM vs. ISO 6946 & At least 7 days & $30 \%$ \\
\hline Evangelisti et al. [15] & $\begin{array}{l}\text { Late } 1800 \text { s, early } 1950 s, \\
\text { and } 2000 \text { s }\end{array}$ & -HFM vs. ISO 6946 & 8,12 and 7 days & $58 \%$ \\
\hline Ficco et al. [21] & $\begin{array}{l}1965,1970,1994,2000 \\
2010, \text { and } 2015\end{array}$ & $\begin{array}{l}\text {-HFM vs. nominal design } \\
\text { data and technical data } \\
\text { available in Italian } \\
\text { standard } \\
\text {-HFM vs. endoscopic } \\
\text { analysis and core } \\
\text { samplings }\end{array}$ & Longer than $72 \mathrm{~h}$ & $24 \%$ to $90 \%$ \\
\hline Walker and Pavía [65] & $\begin{array}{c}\text { 1805, insulated between } \\
\text { December } 2013 \text { and } \\
\text { April } 2014\end{array}$ & $\begin{array}{c}\text {-HFM vs. } \\
\text { laboratory-measured and } \\
\text { provider values }\end{array}$ & n.a. & $20 \%$ \\
\hline Gaspar et al. [54] & $1992,1960,2007$ & -HFM vs. ISO 6946 & $72 \mathrm{~h}$ & $10 \%$ \\
\hline $\begin{array}{l}\text { Bros Williamson } \\
\text { et al. [33] }\end{array}$ & 2012 & -HFM vs. ISO 6946 & 14 to 21 days & $27 \%$ \\
\hline Lucchi [12] & 13th-20th century & $\begin{array}{l}\text {-HFM vs. tabulated design } \\
\text { method vs. abacus of } \\
\text { masonry structures vs. } \\
\text { analytical calculation }\end{array}$ & $\begin{array}{c}-7 \text { days for walls } \\
\text { thickness less than } \\
0.9 \mathrm{~m} \\
-14 \text { days for walls } \\
\text { thickness in the range } \\
0.9-1.1 \mathrm{~m}\end{array}$ & $27 \%$ \\
\hline Lucchi [66] & 12th-18th century & $\begin{array}{l}\text {-HFM vs. ISO } 6946 \text { using } \\
\text { standard suggestions from } \\
\text { UNI } 10351 \text { and UNI } 1745\end{array}$ & $\begin{array}{c}-7 \text { days for walls } \\
\text { thickness less than } \\
0.9 \mathrm{~m} \\
-14 \text { days for walls } \\
\text { thickness in the range } \\
0.9-1.1 \mathrm{~m} \\
\end{array}$ & $31 \%$ \\
\hline $\begin{array}{l}\text { Hoffmann and } \\
\text { Geissler [25] }\end{array}$ & $\begin{array}{c}1600,1850,1905,1925, \\
1953,1962 / 63, \text { and } 1965\end{array}$ & -HFM vs. ISO 6946 & At least $72 \mathrm{~h}$ & $25 \%$ \\
\hline Evangelisti et al. [24] & 2013 & -HFM vs. ISO 6946 & At least 7 days & $18 \%$ \\
\hline \multirow[t]{2}{*}{ Evangelisti et al. [60] } & 2013 & $\begin{array}{c}\text {-HFM vs. ISO } 6946 \\
\text { (different seasons and wall } \\
\text { orientations) } \\
\text {-Data post-processing }\end{array}$ & At least 7 days & $\begin{array}{c}18 \% \text { to } 20 \% \\
\text { (1\% to } 6 \% \text { after post processing) }\end{array}$ \\
\hline & ${ }^{1}$ Percentage differ & ce obtained trough $\left[\frac{\text { Experimer }}{T}\right.$ & retical $] \times 100$. & \\
\hline
\end{tabular}

\subsection{THM Method}

By applying the THM technique, the data processing takes place using the filtered data applying a similar approach to the HFM technique. At present, no dynamic analyses have been proposed for processing data in a different manner. Findings in the literature show that some authors [32] consider the measurement at each timestep as an independent measure to which the filter can be applied, providing the arithmetic mean of the filtered data. Other authors [32,67] apply Equation (5) as a weighted sum of the observations achieved during the measurement period, without detailing whether the data was filtered or not. In order to prevent negative values, the absolute value of the indoor-outdoor temperature difference can be used [19] to make available tests during winter or summer without providing negative results.

Regarding the heat transfer coefficient used for obtaining heat fluxes, findings in the literature show the application of the constant value equal to $7.69 \mathrm{~W} / \mathrm{m}^{2} \mathrm{~K}[32,67]$ (suggested by ISO 6946), $2.5 \mathrm{~W} / \mathrm{m}^{2} \mathrm{~K}$ [19] (or other approximations of the convective heat transfer coefficient), or the sum of convective coefficient found through the dimensionless groups analysis, together with the radiative coefficient $[34,35]$. This approach requires 
a slightly more complex data processing based on temperatures and indoor air velocity data acquisition [68]. It needs the calculation of Grashof $(\mathrm{Gr})$ and Reynolds $(\mathrm{Re})$ numbers, through which computing the Richardson number, known in building physics as the Archimedes (Ar) number [69]:

$$
A r=\frac{G r}{R e^{2}}
$$

Thus, natural, mixed or forced convection conditions can be identified, and the most suitable correlation for the calculation of the Nusselt $(\mathrm{Nu})$ number can be applied. When the Archimedes number is much greater than 10 or much lower than 0.7, pure natural or pure forced convection occur [68]. On the contrary, when the Archimedes number is between these values, the convection is mixed. In functions of natural, mixed or forced convection, the Nusselt number can be computed through the correlations listed in Table 6, where the subscripts $f$ and $n$ stand for forced and natural convection, and the apexes LAM and TURB stand for laminar and turbulent regimes. Consequently, the computation of the $\mathrm{Nu}$ number allows the convective coefficient to be obtained.

Table 6. Available correlations for $\mathrm{Nu}$ calculations for vertical walls (an elaboration from [68]).

\begin{tabular}{|c|c|c|}
\hline Convection & Correlation & Feasibility Condition \\
\hline \multirow[b]{3}{*}{ Natural } & $N u=0.59 \cdot R a^{\frac{1}{4}}$ & $10^{4}<R a<10^{9}$ \\
\hline & $N u=0.10 \cdot R a^{\frac{1}{3}}$ & $10^{9}<R a<10^{13}$ \\
\hline & $N u=\left\{0.825+\frac{0.387 R a^{\frac{1}{6}}}{\left[1+\left(\frac{0.492}{\operatorname{Pr}}\right)^{\frac{9}{16}}\right]^{\frac{8}{27}}}\right.$ & $\forall R a$ \\
\hline Mixed & $N u^{3}=N u_{f}^{3}+N u_{n}^{3}$ & \\
\hline \multirow{2}{*}{ Forced } & $N u_{f}^{L A M}=0.664 \operatorname{Re}^{\frac{1}{2}} \cdot \operatorname{Pr}^{\frac{1}{3}}$ & $\begin{array}{c}\operatorname{Re}<5 \cdot 10^{5} \\
\operatorname{Pr}>0.6\end{array}$ \\
\hline & $N u_{f}^{T U R B}=0.037 R e^{0.8} \cdot \operatorname{Pr}^{\frac{1}{3}}$ & $\begin{array}{c}5 \cdot 10^{5} \leq \operatorname{Re} \leq 10^{7} \\
0.6 \leq \operatorname{Pr} \leq 60\end{array}$ \\
\hline
\end{tabular}

The approach applied to identify the convective heat transfer coefficient can also be based on existing correlations, such as those suggested by Alamdari and Hammond [70], Khalifa and Marshall [71], Churchill and Chu [72], and Fohanno and Polidori [73]. It is worthy to observe that suitable correlations need to be identified according to the features of the room where measurements are performed and heating system boundary conditions [74]. Moreover, in this case, the total heat transfer coefficient needs to be computed as the sum of the convective and radiative parts. A practical problem can be related to furniture and occupant behavior because they can influence the probe positions and the obtained results [24].

Another approach is represented by the application of artificial neural networks through the multilayer perceptrons (MLP) [75]. This method was proposed to determine the U-values of walls considering the heat storage effect. The MLP structure consists of three or more layers. A first input layer, one or more intermediate layers and a final output layer. In each layer, there are neurons connected to those of the next layer through a weighting characterized by different weights. The input neurons do not perform any calculations but send information. Each neuron in the hidden layer sums all inputs, so if that value is greater than the trigger value, an output is generated. The outputs pass to the next layers where the process is repeated and thus, the response of the system can 
be achieved. From a mathematical point of view, the operation can be expressed in the following manner:

$$
z_{k}=\sigma\left[\sum_{j=1}^{M} w_{k j}^{(2)} \sigma\left(\sum_{i=0}^{d} w_{j i}^{(1)} x_{i}\right)+w_{10}^{(2)} y_{0}\right]
$$

where $z_{k}$ is the output of the final layer, $w_{k j}^{(2)}$ are the weights of the output layer, $\sigma$ is the activation function, $w_{j i}^{(1)}$ are the weights of the hidden layer, $x_{i}$ are the values of the input layer, finally $w_{10}^{(2)}$ and $y_{0}$ are the weight and the input value of the bias neuron of the hidden layer, respectively. The MLP estimates internal and external air temperatures, and the inner surface temperature of the wall. Other variables required to obtain the U-value of the wall are the average temperature differences from the first $24 \mathrm{~h}$, both internal and external. Moreover, the wall thickness, the time interval between the measurements and the building period are required inputs. The MLP must be trained through backward propagation. The training process can be carried out through datasets composed of a rather large number of subsets. The multilayer perceptron did not require data post-processing to achieve representative results, thus reducing the time required for the calculation procedure.

It is possible to observe that further investigations are needed to establish general criteria for employing the THM technique, also in terms of convection correlation.

A concise overview of the THM method with deviations of declared results is provided in Table 7. Studies in which the methodological approach is based on the comparison between the results found using the THM method and theoretical calculation could be affected by inaccuracies on assigned thermal conductivities or on assigned surface heat transfer coefficients. On the other hand, when compared with the HFM method, the assessment of heat fluxes through the THM approach is not affected by the heating system power being on, which causes a large increase in the heat flux measured by the heat flux sensor [35].

Table 7. Research papers based on the THM technique.

\begin{tabular}{|c|c|c|c|}
\hline Authors & $\begin{array}{l}\text { Building Construction } \\
\text { Period }\end{array}$ & Methodological Approach & $\begin{array}{l}\text { Average Percentage Difference } \\
\text { between the Obtained Values }{ }^{1}\end{array}$ \\
\hline Cuerda et al. [76] & $\begin{array}{l}\text { Constructed in } 1972 \text { and retrofitted } \\
\text { in } 2011\end{array}$ & $\begin{array}{l}\text {-THM vs. calculation based on } \\
\text { Spanish regulation and databases }\end{array}$ & $31 \%$ \\
\hline Buzatu et al. [77] & n.a. & $\begin{array}{l}\text {-THM vs. theoretical calculation } \\
\text { based on MC001/2009 }\end{array}$ & $42 \%$ \\
\hline Bienvenido-Huertas et al. [75] & from 1950 to 2018 & $\begin{array}{l}\text { THM vs. theoretical calculation } \\
\text { (using the MLP approach) }\end{array}$ & $<20 \%$ \\
\hline Bienvenido-Huertas et al. [78] & from 1950 to 2018 & $\begin{array}{l}\text { THM vs. HFM (using the } \\
\text { MLP approach) }\end{array}$ & $-4 \%$ to $7.5 \%$ \\
\hline Andújar Márquez et al. [19] & n.a & THM vs. HFM & $2 \%$ \\
\hline Bienvenido-Huertas et al. [32] & 1966, 1981, and 2004 & $\begin{array}{c}\text { THM vs. HFM (using } \\
7.69 \mathrm{~W} / \mathrm{m}^{2} \mathrm{~K} \text {, as indicated by } \\
\text { ISO 6946) }\end{array}$ & $\begin{array}{l}4 \% \text { to } 37 \% \text { (winter) } \\
7 \% \text { to } 62 \% \text { (summer) } \\
19 \% \text { to } 83 \% \text { (autumn) }\end{array}$ \\
\hline Kim et al. [67] & 1978, 1979, 1989, and 1991 & THM vs. HFM & $0.3 \%$ to $5 \%$ \\
\hline Kim et al. [79] & 1982, 1983, 1988, and 1994 & THM vs. HFM & $6 \%$ to $17 \%$ \\
\hline Evangelisti et al. [15] & 1950,1960 and 2000 & $\begin{array}{l}\text { THM vs. HFM (in functions of } \\
\text { different existing correlations for } \\
\text { the convective coefficient) }\end{array}$ & $31 \%$ to $32 \%$ \\
\hline Evangelisti et al. [24] & 2013 & $\begin{array}{l}\text { THM vs. HFM (using } 7.69 \\
\mathrm{~W} / \mathrm{m}^{2} \mathrm{~K} \text {, as indicated by } \\
\text { ISO } 6946 \text { ) }\end{array}$ & $37 \%$ to $143 \%$ \\
\hline
\end{tabular}


Table 7. Cont.

\begin{tabular}{ccc}
\hline Authors & $\begin{array}{c}\text { Building Construction } \\
\text { Period }\end{array}$ & $\begin{array}{c}\text { Methodological Approach } \\
\text { between the Obtained Values } \mathbf{1}\end{array}$ \\
\hline Evangelisti et al. [35] & $1960 \quad \begin{array}{c}\text { THM vs. HFM (using both the } \\
\text { dimensionless groups approach } \\
\text { and } 7.69 \mathrm{~W} / \mathrm{m}^{2} \mathrm{~K} \text {, as indicated by } \\
\text { ISO 6946) }\end{array}$ \\
\hline 1 Percentage difference obtained through $\left[\frac{\text { Experimental }- \text { Theoretical }}{\text { Theoretical }}\right] \times 100$ or $\left[\frac{T H M-H F M}{H F M}\right] \times 100$.
\end{tabular}

It can be seen that the THM method provides encouraging results even if not yet fully studied by the scientific community. For this reason, this method should be further investigated due to the advantages of being fast, simple, and less expensive than the HFM method and other experimental approaches.

It can be noticed that the THM method (together with the HFM method) have been applied by Bienvenido-Huertas et al. [80] to characterize the periodic thermal properties of walls using the random forest (RF) and the MLP algorithms. RF is a tree-type algorithm, effective for large datasets and able to provide smaller errors and variances compared to other algorithms. Through this approach, the authors found periodic thermal transmittance (and time shift), decrement factor, external thermal admittance (and time shift), internal thermal admittance (and time shift), external and internal areal heat capacity. The outcomes of this study revealed that HFM and THM provided satisfying estimates. The percentage differences and the statistical parameters (coefficient of determination $\mathrm{R}^{2}$, mean absolute error and root mean square error) for the two methods showed similar values, even if the statistical parameters, referred to the THM method, were slightly lower. On the contrary, the THM method provided more accurate estimates for two of the three investigated walls, highlighting that both approaches allowed to accurately characterize the periodic thermal properties.

\section{Conclusions}

It is well-known that on-site measurements are suitable for verifying the actual thermal performance of existing buildings. Performance assessed on-site, under actual thermal conditions, can substantially vary from the theoretical values. Therefore, experimental measurements are essential for better comprehending the thermal behavior of building components, applying sensors. Starting from this, a review based on the latest scientific papers focused on the HFM method and the THM method was done.

The bibliographic research allowed to conclude that the HFM is a standardized nondestructive method, well-developed for research studies in cold regions (characterized by high indoor-outdoor temperature differences). Nevertheless, the environmental requirements are demanding. Findings in the literature highlight metrological errors related to the heat flow sensors: inaccurate installations cause uncertainties ranging from $26 \%$ to $30 \%$; poor contacts, $2 \%$ to $5 \%$; non-one-dimensional heat flux, $1 \%$ to $5 \%$; wall orientation, $37 \%$; moisture up to $71 \%$; and different heights among sensors, $17 \%$ to $22 \%$. Despite the two standardized methods for HFM data, different approaches for data rejection have been proposed in the literature. However, additional studies are necessary to identify the optimum dataset size, better considering measurement duration and frequency of data collection. High thermal gradients are difficult to achieve under warm climatic conditions, with subsequent limitations of the HFM method. For instance, in Mediterranean cities air temperature values lower than $10^{\circ} \mathrm{C}$ are infrequent, thus it is not frequent to observe an average indoor-outdoor air temperature difference higher than $10^{\circ} \mathrm{C}$. Few studies have been conducted with small temperature gradients and during summer, showing that the seasonal limits have not been extensively analyzed. Starting from this, further efforts should be made to identify standardized post-processing procedures capable of containing errors deriving from non-optimal environmental conditions. The data selection could also not be made by technicians, thus obtaining incorrect results. These aspects become even 
more relevant when placed side by side with specific environmental conditions protracted over time that could unevenly alter the performance of walls in buildings. In these cases, one-spot measurements may therefore not be representative of the entire building and walls characterized by a non-optimal orientation need to be investigated.

On the other hand, the THM method can be considered a promising technique, showing advantages of being fast, simple, and less expensive than the HFM method. However, much progress is needed to collect more case studies that are able to provide much more data (also in a future perspective for possible standardization of the method). In THM, heat flow sensors are not required, so their measurement errors can be excluded. The validity of the THM results is not affected by the test period when there is a strong difference in temperature and the thermal conditions are stable. This method can rapidly provide representative results. For THM, the main issue is related to the total heat transfer coefficient. There is no agreement regarding the value to use, and new approaches based on the dimensionless parameter analysis or artificial neural networks have been proposed. A practical problem related to both HFM and THM methods can be related to furniture and building air-conditioning systems because they can cause specific thermo-fluid dynamic phenomena able to influence the results due to the probe positions.

Future studies should address several issues. HFM measurements need to be better investigated in warm climates where high thermal gradients are challenging. Many studies have been conducted applying the HFM approach but, on the contrary, there is still a lack of in-depth studies that allow more detailed conclusions to be drawn on the THM method. Therefore, further research should be carried out to evaluate the convection correlation for the THM method. Considering the approach based on the dimensionless parameters analysis, detailed investigations about the hot-wire anemometer use and uncertainty contribution can be useful to move towards a potential future method standardization. The THM method should be further investigated due to the advantages of being fast, simple, and less expensive than other existing techniques.

Author Contributions: Conceptualization, L.E.; methodology, L.E., A.S., R.D.L.V. and S.A.S.; data curation, L.E. and A.S.; writing-original draft preparation, L.E. and A.S.; writing-review and editing, R.D.L.V. and S.A.S.; supervision, R.D.L.V. and S.A.S. All authors have read and agreed to the published version of the manuscript.

Funding: This research received no external funding.

Institutional Review Board Statement: Not applicable.

Informed Consent Statement: Not applicable.

Data Availability Statement: Not applicable.

Conflicts of Interest: The authors declare no conflict of interest.

\section{References}

1. Carvalho, J.P.; Bragança, L.; Mateus, R. Sustainable building design: Analysing the feasibility of BIM platforms to support practical building sustainability assessment. Comput. Ind. 2021, 127, 103400. [CrossRef]

2. Nardi, I.; Lucchi, E.; de Rubeis, T.; Ambrosini, D. Quantification of heat energy losses through the building envelope: A state-of-the-art analysis with critical and comprehensive review on infrared thermography. Build. Environ. 2018, 146, 190-205. [CrossRef]

3. Gan, V.J.; Deng, M.; Tse, K.; Chan, C.M.; Lo, I.M.; Cheng, J.C. Holistic BIM framework for sustainable low carbon design of high-rise buildings. J. Clean. Prod. 2018, 195, 1091-1104. [CrossRef]

4. Yadav, M.; Agarwal, M. Biobased building materials for sustainable future: An overview. Mater. Today Proc. 2021, 43, 2895-2902. [CrossRef]

5. Desogus, G.; Mura, S.; Ricciu, R. Comparing different approaches to in situ measurement of building components thermal resistance. Energy Build. 2011, 43, 2613-2620. [CrossRef]

6. Oral, G.K.; Yilmaz, Z. The limit U values for building envelope related to building form in temperate and cold climatic zones. Build. Environ. 2002, 37, 1173-1180. [CrossRef]

7. Prada, A.; Cappelletti, F.; Baggio, P.; Gasparella, A. On the effect of material uncertainties in envelope heat transfer simulations. Energy Build. 2014, 71, 53-60. [CrossRef] 
8. Ballarini, I.; Corrado, V.; Madonna, F.; Paduos, S.; Ravasio, F. Energy refurbishment of the Italian residential building stock: Energy and cost analysis through the application of the building typology. Energy Policy 2017, 105, 148-160. [CrossRef]

9. ISO 6946. Building Components and Building Elements—Thermal Resistance and Thermal Transmittance-Calculation Methods; ISO: Geneva, Switzerland, 2017.

10. Sassine, E.; Cherif, Y.; Antczak, E. Parametric identification of thermophysical properties in masonry walls of buildings. J. Build. Eng. 2019, 25, 100801. [CrossRef]

11. Biddulph, P.; Gori, V.; Elwell, C.A.; Scott, C.; Rye, C.; Lowe, R.; Oreszczyn, T. Inferring the thermal resistance and effective thermal mass of a wall using frequent temperature and heat flux measurements. Energy Build. 2014, 78, 10-16. [CrossRef]

12. Lucchi, E. Thermal transmittance of historical brick masonries: A comparison among standard data, analytical calculation procedures, and in situ heat flow meter measurements. Energy Build. 2017, 134, 171-184. [CrossRef]

13. Nardi, I.; de Rubeis, T.; Perilli, S. Ageing Effects on the Thermal Performance of Two Different Well-insulated Buildings. Energy Procedia 2016, 101, 1050-1057. [CrossRef]

14. Antonyová, A.; Korjenic, A.; Antony, P.; Korjenic, S.; Pavlušová, E.; Pavluš, M.; Bednar, T. Hygrothermal properties of building envelopes: Reliability of the effectiveness of energy saving. Energy Build. 2013, 57, 187-192. [CrossRef]

15. Staszczuk, A.; Kuczyński, T. The impact of wall and roof material on the summer thermal performance of building in a temperate climate. Energy 2021, 228, 120482. [CrossRef]

16. De Luxan Garcia de Diego, M.; Munoz, G.G.; Lopez, E.R. Towards new energy accounting in residential building. Inf. Constr. 2015, 67, 1-10

17. Bienvenido-Huertas, D.; Moyano, J.; Marín, D.; Fresco-Contreras, R. Review of in situ methods for assessing the thermal transmittance of walls. Renew. Sustain. Energy Rev. 2018, 102, 356-371. [CrossRef]

18. Teni, M.; Krstić, H.; Kosiński, P. Review and comparison of current experimental approaches for in-situ measurements of building walls thermal transmittance. Energy Build. 2019, 203, 109417. [CrossRef]

19. Andújar Márquez, J.M.; Martínez Bohórquez, M.Á.; Gómez Melgar, S. A New Metre for Cheap, Quick, Reliable and Simple Thermal Transmittance (U-Value) Measurements in Buildings. Sensors 2017, 17, 2017. [CrossRef]

20. Evangelisti, L.; Guattari, C.; Gori, P.; Vollaro, R.D.L.; Asdrubali, F. Experimental investigation of the influence of convective and radiative heat transfers on thermal transmittance measurements. Int. Commun. Heat Mass Transf. 2016, 78, 214-223. [CrossRef]

21. Ficco, G.; Iannetta, F.; Ianniello, E.; Alfano, F.R.D.; Dell'Isola, M. U-value in situ measurement for energy diagnosis of existing buildings. Energy Build. 2015, 104, 108-121. [CrossRef]

22. Jelle, B.P. Accelerated climate ageing of building materials, components and structures in the laboratory. J. Mater. Sci. 2012, 47, 6475-6496. [CrossRef]

23. ISO 9869-1. Thermal Insulation-Building Elements_In-Situ Measurement of Thermal Resistance and Thermal Transmittance Heat Flow Meter Method; ISO: Geneva, Switzerland, 2014.

24. Evangelisti, L.; Guattari, C.; Asdrubali, F. Comparison between heat-flow meter and Air-Surface Temperature Ratio techniques for assembled panels thermal characterization. Energy Build. 2019, 203, 109441. [CrossRef]

25. Hoffmann, C.; Geissler, A. The prebound-effect in detail: Real indoor temperatures in basements and measured versus calculated U-values. Energy Procedia 2017, 122, 32-37. [CrossRef]

26. Baker, P. Technical Paper 10: U-Values and Traditional Buildings-In Situ Measurements and Their Comparisons to Calculated Values; SEMANTIC SCHOLAR: Seattle, WA, USA, 2011.

27. Peng, C.; Wu, Z. In situ measuring and evaluating the thermal resistance of building construction. Energy Build. 2008, 40, 2076-2082. [CrossRef]

28. Gaspar, K.; Casals, M.; Gangolells, M. In situ measurement of façades with a low U-value: Avoiding deviations. Energy Build. 2018, 170, 61-73. [CrossRef]

29. Albatici, R.; Tonelli, A.M.; Chiogna, M. A comprehensive experimental approach for the validation of quantitative infrared thermography in the evaluation of building thermal transmittance. Appl. Energy 2015, 141, 218-228. [CrossRef]

30. Zalewski, L.; Lassue, S.; Rousse, D.; Boukhalfa, K. Experimental and numerical characterization of thermal bridges in prefabricated building walls. Energy Convers. Manag. 2010, 51, 2869-2877. [CrossRef]

31. Guattari, C.; Evangelisti, L.; Gori, P.; Asdrubali, F. Influence of internal heat sources on thermal resistance evaluation through the heat flow meter method. Energy Build. 2017, 135, 187-200. [CrossRef]

32. Bienvenido-Huertas, D.; Rodríguez-Álvaro, R.; Moyano, J.J.; Rico, F.; Marín, D. Determining the U-Value of Façades Using the Thermometric Method: Potentials and Limitations. Energies 2018, 11, 360. [CrossRef]

33. Bros-Williamson, J.; Garnier, C.; I Currie, J. A longitudinal building fabric and energy performance analysis of two homes built to different energy principles. Energy Build. 2016, 130, 578-591. [CrossRef]

34. Evangelisti, L.; Guattari, C.; de Rubeis, T. Preliminary analysis of the influence of environmental boundary conditions on convective heat transfer coefficients. J. Phys. Conf. Ser. 2021, 1868, 012024. [CrossRef]

35. Evangelisti, L.; Guattari, C.; Fontana, L.; Vollaro, R.D.L.; Asdrubali, F. On the ageing and weathering effects in assembled modular facades: On-site experimental measurements in an Italian building of the 1960s. J. Build. Eng. 2021, 45, 103519. [CrossRef]

36. Cesaratto, P.G.; De Carli, M.; Marinetti, S. Effect of different parameters on the in situ thermal conductance evaluation. Energy Build. 2011, 43, 1792-1801. [CrossRef]

37. Trethowen, H. Measurement errors with surface-mounted heat flux sensors. Build. Environ. 1986, 21, 41-56. [CrossRef] 
38. Cucumo, M.; De Rosa, A.; Ferraro, V.; Kaliakatsos, D.; Marinelli, V. A method for the experimental evaluation in situ of the wall conductance. Energy Build. 2006, 38, 238-244. [CrossRef]

39. Meng, X.; Yan, B.; Gao, Y.; Wang, J.; Zhang, W.; Long, E. Factors affecting the in situ measurement accuracy of the wall heat transfer coefficient using the heat flow meter method. Energy Build. 2015, 86, 754-765. [CrossRef]

40. Cucumo, M.; Ferraro, V.; Kaliakatsos, D.; Mele, M. On the distortion of thermal flux and of surface temperature induced by heat flux sensors positioned on the inner surface of buildings. Energy Build. 2018, 158, 677-683. [CrossRef]

41. Gaspar, K.; Casals, M.; Gangolells, M. Influence of HFM Thermal Contact on the Accuracy of In Situ Measurements of Façades' U-Value in Operational Stage. Appl. Sci. 2021, 11, 979. [CrossRef]

42. Ahmad, A.; Maslehuddin, M.; Al-Hadhrami, L.M. In situ measurement of thermal transmittance and thermal resistance of hollow reinforced precast concrete walls. Energy Build. 2014, 84, 132-141. [CrossRef]

43. Wang, F.; Wang, D.; Wang, X.; Yao, J. A data analysis method for detecting wall thermal resistance considering wind velocity in situ. Energy Build. 2010, 42, 1647-1653. [CrossRef]

44. Litti, G.; Khoshdel, S.; Audenaert, A.; Braet, J. Hygrothermal performance evaluation of traditional brick masonry in historic buildings. Energy Build. 2015, 105, 393-411. [CrossRef]

45. Evangelisti, L.; Guattari, C.; Asdrubali, F. Influence of heating systems on thermal transmittance evaluations: Simulations, experimental measurements and data post-processing. Energy Build. 2018, 168, 180-190. [CrossRef]

46. Bienvenido-Huertas, D. Assessing the Environmental Impact of Thermal Transmittance Tests Performed in Façades of Existing Buildings: The Case of Spain. Sustainability 2020, 12, 6247. [CrossRef]

47. Albatici, R.; Tonelli, A.M. Infrared thermovision technique for the assessment of thermal transmittance value of opaque building elements on site. Energy Build. 2010, 42, 2177-2183. [CrossRef]

48. Gori, V.; Elwell, C. Estimation of thermophysical properties from in-situ measurements in all seasons: Quantifying and reducing errors using dynamic grey-box methods. Energy Build. 2018, 167, 290-300. [CrossRef]

49. Genova, E.; Fatta, G. The thermal performances of historic masonry: In-situ measurements of thermal conductance on calcarenite stone walls in Palermo. Energy Build. 2018, 168, 363-373. [CrossRef]

50. Aittomäki, A. Determination of the overall heat transfer coefficient of multilayer structures under non-steady-state conditions. In CIB Session Working Paper; CIB: Hongkong, China, 1972.

51. Juhl, R.; Kristensen, N.R.; Bacher, P.; Kloppenborg, J.; He, M. CTSM-R User Guide. 2013. Available online: http:/ / ctsm.info/pdfs/ userguide.pdf (accessed on 6 January 2022).

52. Gutschker, O. LORD-modelling and identification software for thermal systems. In User Manual; BTU Cottbus: Cottbus, Germany, 2004.

53. Van Dijk, D.; der Linden, V.G.I. For S.E. and Informatics, E.S.A.S.C. of the E. Communities, MRQT User Guide; Manual for MRQT and the Package MRQT/PASTA; Commission of the European Communities: Luxembourg, 1994.

54. Gaspar, K.; Casals, M.; Gangolells, M. A comparison of standardized calculation methods for in situ measurements of façades U-value. Energy Build. 2016, 130, 592-599. [CrossRef]

55. Atsonios, I.A.; Mandilaras, I.D.; Kontogeorgos, D.A.; Founti, M.A. A comparative assessment of the standardized methods for the in-situ measurement of the thermal resistance of building walls. Energy Build. 2017, 154, 198-206. [CrossRef]

56. Gaspar, K.; Casals, M.; Gangolells, M. Review of criteria for determining HFM minimum test duration. Energy Build. 2018, 176, 360-370. [CrossRef]

57. Cesaratto, P.G.; De Carli, M. A measuring campaign of thermal conductance in situ and possible impacts on net energy demand in buildings. Energy Build. 2013, 59, 29-36. [CrossRef]

58. Tejedor, B.; Casals, M.; Gangolells, M.; Roca-Ramon, X. Quantitative internal infrared thermography for determining in-situ thermal behaviour of façades. Energy Build. 2017, 151, 187-197. [CrossRef]

59. Blanco, I.; Convertino, F.; Schettini, E.; Vox, G. Energy analysis of a green façade in Summer: An experimental test in Mediterranean climate conditions. Energy Build. 2021, 245, 111076. [CrossRef]

60. Evangelisti, L.; Guattari, C.; Vollaro, R.D.L.; Asdrubali, F. A methodological approach for heat-flow meter data post-processing under different climatic conditions and wall orientations. Energy Build. 2020, 223, 110216. [CrossRef]

61. Doran, S. Safety and Health Business Plan, Field Investigations of the Thermal Performance of Construction Elements as Built. Available online: https:/ / www.researchgate.net/publication/277854674_Field_Investigations_of_the_thermal_performance_ of_construction_elements_as_built. (accessed on 6 January 2022).

62. Rye, C.; Scott, C. The SPAB Research Report 1. U-Value Report; SPAB: London, UK, 2010.

63. Rhee-Duverne, S.; Baker, P. Research into the Thermal Performance of Traditional Brick Walls, English Heritage Report; Historic England: London, UK, 2013.

64. Asdrubali, F.; D'Alessandro, F.; Baldinelli, G.; Bianchi, F. Evaluating in situ thermal transmittance of green buildings masonries-A case study. Case Stud. Constr. Mater. 2014, 1, 53-59. [CrossRef]

65. Walker, R.; Pavía, S. Thermal performance of a selection of insulation materials suitable for historic buildings. Build. Environ. 2015, 94, 155-165. [CrossRef]

66. Lucchi, E. Thermal transmittance of historical stone masonries: A comparison among standard, calculated and measured data. Energy Build. 2017, 151, 393-405. [CrossRef] 
67. Kim, S.-H.; Kim, J.-H.; Jeong, H.-G.; Song, K.-D. Reliability Field Test of the Air-Surface Temperature Ratio Method for In Situ Measurement of U-Values. Energies 2018, 11, 803. [CrossRef]

68. Çengel, Y.A. Heat Transfer: A Practical Approach; McGraw-Hill: New York, NY, USA, 2004.

69. Walikewitz, N.; Jänicke, B.; Langner, M.; Meier, F.; Endlicher, W. The difference between the mean radiant temperature and the air temperature within indoor environments: A case study during summer conditions. Build. Environ. 2015, 84, 151-161. [CrossRef]

70. Alamdari, F.; Hammond, G.P. Improved data correlations for buoyancy-driven convection in rooms. Build. Serv. Eng. Res. Technol. 1983, 4, 106-112. [CrossRef]

71. Khalifa, A.J.; Marshall, R. Validation of heat transfer coefficients on interior building surfaces using a real-sized indoor test cell. Int. J. Heat Mass Transf. 1990, 33, 2219-2236. [CrossRef]

72. Churchill, S.W.; Chu, H.H. Correlating equations for laminar and turbulent free convection from a vertical plate. Int. J. Heat Mass Transf. 1975, 18, 1323-1329. [CrossRef]

73. Fohanno, S.; Polidori, G. Modelling of natural convective heat transfer at an internal surface. Energy Build. 2006, 38, 548-553. [CrossRef]

74. Camci, M.; Karakoyun, Y.; Acikgoz, O.; Dalkilic, A.S. A comparative study on convective heat transfer in indoor applications. Energy Build. 2021, 242, 110985. [CrossRef]

75. Bienvenido-Huertas, D.; Moyano, J.; Jiménez, C.E.R.; Marín, D. Applying an artificial neural network to assess thermal transmittance in walls by means of the thermometric method. Appl. Energy 2019, 233-234, 1-14. [CrossRef]

76. Cuerda, E.; Guerra-Santin, O.; Neila, F.J.; Romero, N. Evaluation and comparison of building performance in use through on-site monitoring and simulation modelling. In Proceedings of the 3rd IBPSA-England Conference BSO 2016, Great North Museum, Newcastle, UK, 12-14 September 2016.

77. Buzatu, G.-C.; Stan-Ivan, F.-E.; Mircea, P.-M.; Manescu, L.-G. Thermal transmittance determination for different components of buildings. In Proceedings of the 2017 International Conference on Optimization of Electrical and Electronic Equipment (OPTIM) \& 2017 Intl Aegean Conference on Electrical Machines and Power Electronics (ACEMP), Brasov, Romania, 25-27 May 2017; pp. 227-232.

78. Bienvenido-Huertas, D.; Rubio-Bellido, C.; Pérez-Ordóñez, J.L.; Moyano, J. Optimizing the evaluation of thermal transmittance with the thermometric method using multilayer perceptrons. Energy Build. 2019, 198, 395-411. [CrossRef]

79. Kim, S.-H.; Lee, J.-H.; Kim, J.-H.; Yoo, S.-H.; Jeong, H.-G. The Feasibility of Improving the Accuracy of In Situ Measurements in the Air-Surface Temperature Ratio Method. Energies 2018, 11, 1885. [CrossRef]

80. Bienvenido-Huertas, D.; Rubio-Bellido, C.; Solís-Guzmán, J.; Oliveira, M.J. Experimental characterisation of the periodic themal properties of walls using artificial intelligence. Energy 2020, 203, 117871. [CrossRef] 